\title{
A Simple Test for Thermomechanical Evaluation of Ceramic Fibers
}

Gregory N. Morscher

Case Western Reserve University

Cleveland, Ohio

and

James A. DiCarlo

Lewis Research Center

Cleveland, Ohio.

April 1991

(NASA-TM-103767) A SIMPLE TEST FOR

$191-21309$

THERMOMECHANICAL EVALUATION OF CERAMIC

FIEFRS (NASA) $10 \mathrm{P}$ CSCL 116

Unclas

G3/27 0008410

\section{N/SN}




\title{
A SIMPLE TEST FOR THERMOMECHANICAL EVALUATION OF CERAMIC FIBERS
}

\author{
Gregory N. Morscher* \\ Case Western Reserve University \\ Cleveland, Ohio 44115 \\ and \\ James A. DiCarlo \\ National Aeronautics and Space Administration \\ Lewis Research Center \\ Cleveland, Ohio 44135
}

\section{ABSTRACT}

A simple bend stress relaxation (BSR) test has been developed to measure the creep related properties of ceramic fibers and whiskers. The test was applied to a variety of commercial and developmental si-based fibers to demonstrate capabilities and to evaluate the relative creep resistance of the fibers at 1200 and $1400^{\circ} \mathrm{C}$. The implications of these results and the advantages of the BSR test over typical tensile creep tests are discussed.

\section{INTRODUCTION}

Ceramic matrix composites (CMC's) reinforced by continuous or long length ceramic fibers are currently being considered for a variety of high temperature aerospace components. Since these components will typically experience thermal and mechanical stresses at service temperatures to $1200^{\circ} \mathrm{C}$ and above, it is of utmost importance that under these conditions the ceramic fibers display long term strength stability and creep resistance as well as many other important properties (ref. 1). To date several commercial and experimental ceramic fiberg are being used to demonstrate feasibility for cmc fabrication and for good CMC structural performance at low temperatures. However, for the very high temperature applications where CMC'g will have the greatest technical payoff, these currently available fibers are inadequate primarily due to thermal and stress-induced degradation (refs. I to 4). New fibers need to be developed to overcome these deficiencies, and simple thermomechanical tests need to be devised to help guide the processing of these fibers.

To minimize stress-induced degradation, the key fiber thermomechanical property to be measured and understood is creep since this property not only controls fiber dimensional stability but also fiber intrinsic strength. Unfortunately, measuring creep of ceramics under tensile loading is difficult (ref. 5). This is especially true with small diameter fibers which are often degraded by air test environments and can be easily fractured by the application of strain and stress sensors (ref. 6). To avoid these problems, a simple fiber bend stress relaxation (BSR) test was developed and is described here. This test, which is a modification of previous work (ref. 7 ), can measure the effects of time, temperature, and applied strain on the creep-related BSR of

\footnotetext{
*NASA Resident Research Associate at Lewis Research Center.
} 
any diameter fiber, in any environment, and without the need of contact sensors. Theoretical and experimental details of the BSR test are presented as well as selected high temperature BSR results for a variety of silicon-based ceramic fibers.

\section{TEST METHOD}

For the simplest application of the BSR test, an initial elastic bend strain is imposed on a fiber by tying it into a loop as shown schematically in figure 1. The initial stress, $\sigma_{0}$, and strain, $\varepsilon_{0}$, vary within the fiber by the relations $\sigma_{0}=E \varepsilon_{0}$ and $\varepsilon_{0} \stackrel{=}{=} / R_{0}$, respectively, where $E$ is the fiber elastic modulus, $z$ is the distance from the fiber centroid axis in the loop plane, and $R_{0}$ is the loop radius. The fiber loop is then subjected to a specific time, $t$, temperature, $T$, and environmental treatment. After treatment, the loop is taken back to room temperature where the loop diameter, $2 \mathrm{R}_{0}$, is measured. The applied strain is then removed by breaking the loop at one point and any treatment-induced effects are measured in terms of the

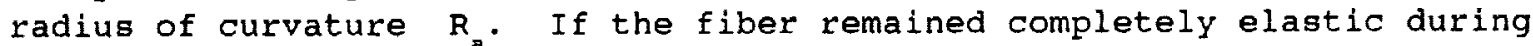
treatment, the broken loop will be straight with no curvature $\left(R_{a}=0\right)$. However, if creep-induced stress relaxation occurred, $R_{a}$ will be finite and typically will decrease with increasing treatment time and temperature.

To quantify the stress relaxation that occurs during treatment, one can define the parameter $m$ which is the ratio of final to initial stress at the treatment temperature (ref. 7). That is,

$$
m=\frac{\sigma\left(t, T, \varepsilon_{o}\right)}{\sigma_{o}\left(O, T, \varepsilon_{o}\right)}=\frac{E \varepsilon_{e}\left(t, T, \varepsilon_{o}\right)}{E \varepsilon_{o}}=\frac{\varepsilon_{o}-\varepsilon_{c}\left(t, T, \varepsilon_{o}\right)}{\varepsilon_{o}}
$$

where $\varepsilon_{e}$ and $\varepsilon_{c}$ are the local elastic strain and treatment-induced creep strain, respectively. For convenience, one can assume that $\varepsilon_{c}$ is 1 inearly proportional to $\varepsilon_{0}$ so that it can be measured by the relation $\varepsilon_{c}=z_{0} / R_{a}$. This assumption of linear strain (stress) dependence is generally valid for polycrystalline ceramics which stress relax (creep) due to grain boundary sliding mechanisms that are either elastically (ref. 8) or diffusionally accommodated (ref. 9). It then follows that the BSR ratio $m$ is only a function of treatment time and temperature and is given by the simple relation

$$
m(t, T)=1-\frac{R_{0}}{R_{a}}
$$

In some cases, $m$ may be found to vary with initial radius $R_{0}$. In these situations, each measurement by equation (2) then represents a weighted average of the local $m$ ratio values within the fiber at a specific applied surface strain equal to $d_{f} / 2 R_{0}$ where $d_{f}$ is the fiber diameter.

\section{EXPERIMENTAL PROCEDURE}

The BSR test was applied to a variety of commercial and experimental silicon-based fibers. These fibers and some information concerning them are listed in table I. For Nicalon, Tyranno, and HPZ fibers, the sizing was removed by soaking the fibers in acetone from 5 to $25 \mathrm{hr}$ in order to better separate individual fibers from the tow. BSR tests generally consisted of 
1 to $100 \mathrm{hr}$ exposures between 900 and $1400^{\circ} \mathrm{C}$ in air. However, vacuum, $0.1 \mathrm{MPa}$ argon, and $138 \mathrm{MPa}$ argon test environments were also used to eliminate oxidation effects or to avoid thermal decomposition. The vacuum and argon treatments were conducted in carbon element furnaces with the fibers placed in grafoil boats to further reduce residual oxygen. The high pressure argon treatment was performed at $1400^{\circ} \mathrm{C}$ in a HIP (hot-isostatic press) apparatus and used only for the Nicalon and HPZ fibers which have potential for thermal decomposition in low pressure environments (ref. 2).

For each test condition, between 4 and 10 fibers were treated at different loop diameters ranging from 20 to $100 \mathrm{~mm}$ for SCS -6 fibers and from 0.25 to $2.5 \mathrm{~mm}$ for the other fibers. However, for the single crystal SiC whiskers, loops could not be tied because only short fiber lengths $(<2 \mathrm{~cm})$ were available. To overcome this problem, BSR was measured by placing the whiskers in the large $R_{0}$ setups shown in figure 2. These jigs, which were made out of alumina for air treatments or graphite for inert treatments, could also be used for low strain BSR measurements on the continuous fibers.

Measurement error for the BSR tests can depend on a variety of factors. For example, occasionally some loops were oval after heat treatment. Loops were only accepted when the variation in $R_{0}$ for the entire loop was less than 5 percent. This variation can result in a maximum error of \pm 0.01 for $m=0.7$ and \pm 0.025 for $m=0.1$. Errors in $m$ can also result from errors in temperature measurement. For example, for errors of $\pm 10^{\circ} \mathrm{C}, m$ values can differ by as much as \pm 0.1 in certain temperature regimes. Also, furnace heatup and cool-down rates can influence $m$. This error is expected to be greatest for the shorter time heat treatments and for the more massive BSR setups, such as those shown by figure 2 .

\section{RESULTS AND DISCUSSION}

The BSR test was first applied to SCS-6 fibers to evaluate the stress relaxation of this fiber type as a function of time, temperature, strain, and environment. The effects of surface strain on $1 \mathrm{hr}$ BSR data for sCS-6 fibers at 1100 and $1200^{\circ} \mathrm{C}$ in air and argon are shown in figure 3 . The results suggest that at these temperatures the $m$ ratio for the scs-6 fiber did not depend on applied strain or oxygen in the test environment. From a practical point of view, these observations were very useful since they eliminated the need to study different loop sizes or to use inert environments only. From a basic point of view, the observation of strain independence for scs-6 stress relaxation supports grain boundary sliding as the principal creep mechanism (ref. 8). Whereas the observation of oxygen independence suggests that as-grown oxide layers have little influence for this large diameter fiber.

Time and temperature-dependent BSR data for the SCS-6 fiber are shown in figure 4 for 1,10 , and $100 \mathrm{hr}$ air tests between 900 and $1400{ }^{\circ} \mathrm{C}$ at a surface strain of $\sim 0.3$ percent. Obviously, below $1400{ }^{\circ} \mathrm{C}$ a considerable amount of creep can take place in the sCS-6 fiber as was found by DiCarlo (ref. 10). If the relaxation mechanism is thermally activated, the activation energy $Q$ can then be determined from the $\Delta(1 / \mathrm{T})$ spacing between the figure 3 curves at a constant $m$ value (cross-cut method) (ref. 11). That is, for one order of magnitude change in time, $Q=2.3 R / \Delta(1 / T)$ where $R$ is the gas constant $(8.314 \mathrm{~J} / \mathrm{mol} / \mathrm{K})$. From these data, an activation energy of $\sim 560 \mathrm{~kJ} / \mathrm{mol} \mathrm{was}$ 
found for the SCS- 6 fiber at $m=0.5$. This value, which appears to be independent of $\mathrm{m}$, is similar to that found by Dicarlo for tensile creep $(480 \mathrm{~kJ} / \mathrm{mol}$ ) (ref. 10). DiCarlo attributes SCS-6 fiber creep to anelastic grain boundary sliding controlled by free silicon diffusion in the grain boundaries.

To rank the creep resistance of the SCS-6 fiber against the other si-based fibers, 1-hr BSR data were measured for all fibers in various environments, Results are shown in figures $5(a)$ and $(b)$ for 1200 and $1400{ }^{\circ} \mathrm{C}$, respectively, for all the ceramic fibers examined. To assure accurate comparisons, multiple fiber types were treated during the same test run and at approximately the same surface strain of 0.3 percent. At $1200^{\circ} \mathrm{C}$, all fibers were heat treated in vacuum or in air. However at $1400^{\circ} \mathrm{C}$, low and high pressure argon test environments were also employed. strain independence was observed for all fibers except for the Nicalon and $\beta$-sic fibers which displayed decreasing $m$ ratio with increasing strain. There was too much scatter to determine strain dependence for the Tyranno fiber. At $1200{ }^{\circ} \mathrm{C}$ all the fibers retained some stress; however the Tyranno fiber was nearly fully relaxed. At $1400{ }^{\circ} \mathrm{C}$, the $\beta$-SiC fiber was the only polycrystalline fiber which still retained some stress. On the other hand, the single crystal Sic whisker at $1400{ }^{\circ} \mathrm{C}$ showed no stress relaxation (no creep). For all fibers, no significant environment effects were observed except for the HPZ fiber which at $1200{ }^{\circ} \mathrm{C}$ had a measurably lower $\mathrm{m}$ ratio in vacuum than air. Presumably this was related to increased thermal decomposition of the fiber in the vacuum environment.

The implications of the results displayed in figure 5 are numerous. From a practical point of view, it appears that currently available si-based polycrystalline fibers display creep-related effects well below $1400{ }^{\circ} \mathrm{C}$. This can be advantageous for composite fabrication approaches in which it may be desirable to creep-form fibers into curved shapes or to relieve bend stresses in woven fiber preforms. However, the existence of stress relaxation implies that dimensional changes can occur which could be detrimental if excessive in critical composite components. In addition, existing data for some of the polycrystalline fibers tested here show an initial loss in fast fracture strength at test temperatures where stress relaxation first occurs (refs. 1 and 3). In that regard, the BSR regults would then suggest that below $1400{ }^{\circ} \mathrm{C}$ the tensile strengths of all the polycrystalline fibers will continually degrade due to creep-related flaw growth mechanisms.

From a basic point of view, the differences observed in the BSR data for the polycrystalline fibers indicate that certain microstructures are more creep resistant than others. As with bulk ceramics, these differences are probably related to such factors as grain size, grain shape, and chemical composition of the grain boundary phase. As microstructural features become better elucidated, one might expect to develop property and processing guidelines for improved polycrystalline fibers with reduced stress relaxation, better creep resistance, and higher use temperatures. The BSR test should be a simple and rapid method for evaluating processing improvements. 


\section{CONCLUSIONS}

The fiber loop test (and its variants) has been shown to be a simple technique for evaluating the thermomechanical stability of ceramic fibers in general and their stress relaxation properties in particular. This study has demonstrated that in comparison to typical tensile creep tests, the BSR offers many advantages. Prime among these is the ability to simply and rapidly evaluate the creep resistance of various fibers at temperatures of interest for advanced composites. For example, in this study it has been shown that all tested polycrystalline silicon-based fibers relax (creep) below $1400{ }^{\circ} \mathrm{C}$. However, significant differences in stress relaxation were observed which suggest that opportunities exist for developing new si-based fibers with improved processing and microstructures. Future research will continue to use the BSR test not only to evaluate fiber improvement but also to determine its relationship to tensile creep (ref. 12), the basic controlling mechanisms, and the practical structural implications for those fibers of high potential for advanced CMC's.

\section{REFERENCES}

1. DiCarlo, J.A.: Fibers for structurally Reliable Metal and Ceramic Composites. J. Met., vol. 37, no. 6, June 1985, pp. 44-49.

2. Jaskowiak, M.H.; and DiCarlo, J.A.: Pressure Effects on the Thermal stability of Silicon Carbide Fibers. J. Am. Ceram. Soc., vol. 72, no. 2, Feb. 1989, pp. 192-197.

3. Tressler, R.E.; and Pysher, D.J.: Mechanical Behavior of High Strength Ceramic Fibers at High Temperatures. Presented at 7 th Conference CIMTEC, Italy. June, 1990.

4. Simon, G.; and Bunsell, A.R.: Creep Behaviour and Structural Characterization at High Temperatures of $\mathrm{Nicalon} \mathrm{SiC} \mathrm{Fibres.} \mathrm{J.} \mathrm{Mater.}$ Sci., vol. 19, no. 11, 1984, pp. 3658-3670.

5. Kandil, F.A.; and Dyson, B.F.: Tensile Creep of Ceramics: the Development of a Testing Facility. Mechanical Testing of Engineering Ceramics at High Temperatures, B.F. Dyson, R.D. Lohr, and R. Morrell, eds., Elsevier, 1988, pp. 151-170.

6. Hughes, J.D.H.: A Review of Techniques for Evaluating Stiff Fibres. Br. Ceram. Trans. J. vol. 87, no. 6, 1988, pp. 181-188.

7. DiCarlo, J.A.: Anelastic Deformation of Boron Fibers. Scripta Metall. vol. 10, no. 2, 1976, pp. 115-119.

8. Nowick, A.S.; and Berry, B.S.: Anelastic Relaxation in Crystalline Solids. Academic Press, 1972.

9. Raj, R.; and Ashby, M.F.: On Grain Boundary Sliding and Diffusional Creep. Metall. Trans., vol. 2, no. 4, 1971, pp. 1113-1127.

10. DiCarlo, J.A.: Creep of Chemically Vapour Deposited SiC Fibers. J. Mater. Sci., vol. 21, no. 1, Jan. 1986, pp. 217-224. 
11. Damask, A.C.; and Dienes, G.J.: Point Defects in Metals, Gordon and Breach, NY, 1963.

12. Morscher, G.N.; DiCarlo, J.A.; and Wagner, T.C.: Fiber Creep Evaluation by Stress Relaxation Measurements. Submitted to Ceram. Eng. Sci. Proc., 1991.

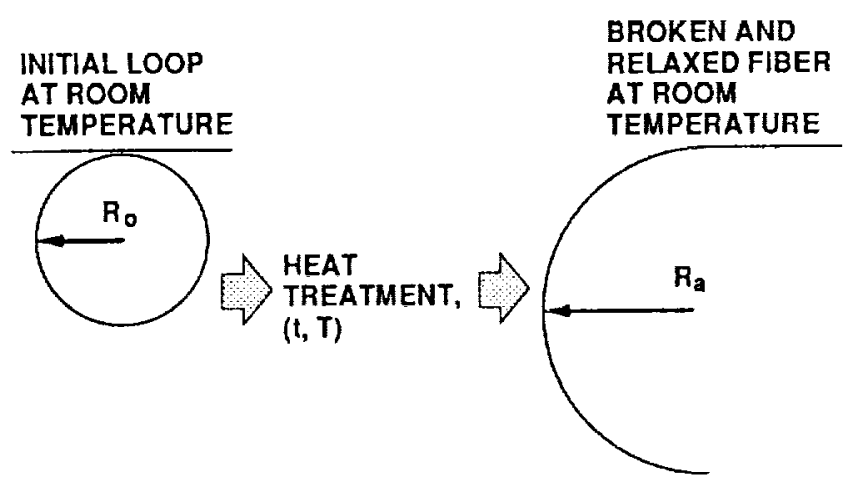

Figure 1.Schematic representation of BSR test using fiber loops.

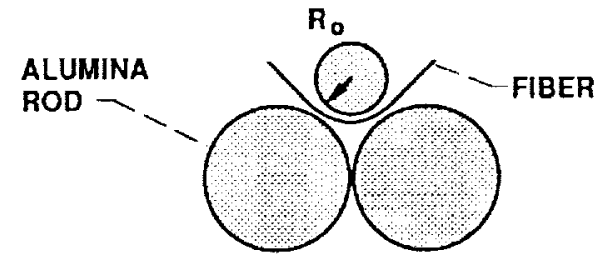

(a) $R_{0}=1 \mathrm{~mm}$.

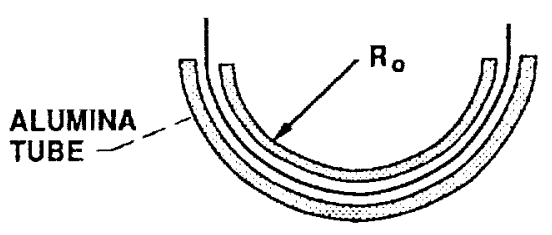

(b) $R_{0}=10 \mathrm{~mm}$.

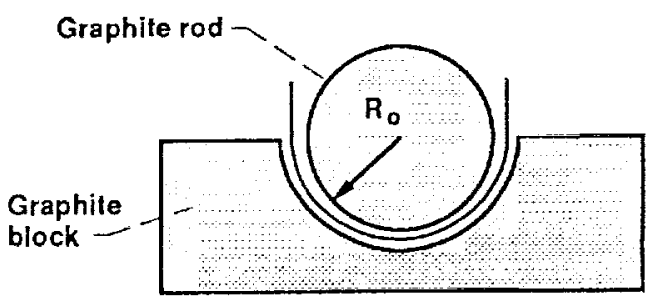

(c) $R_{0}=4 \mathrm{~mm}$.

Figure 2.-Schematic representations of BSR test jigs. For whisker experiments, alumina tubes (a) and (b) were used for air tests. A graphite block and rod (c) was used for argon tests. 


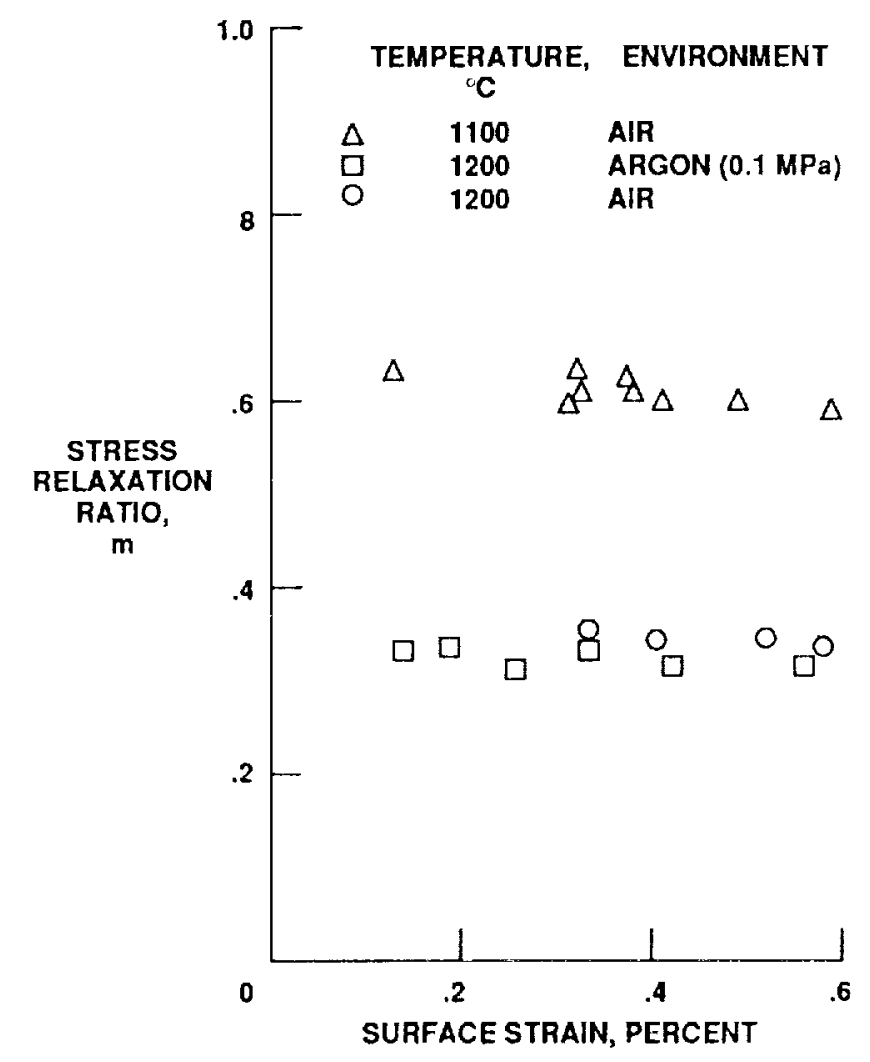

Figure 3. One hour stress relaxation ratio valucs versus applied surface strain for SCS-6 fibers.

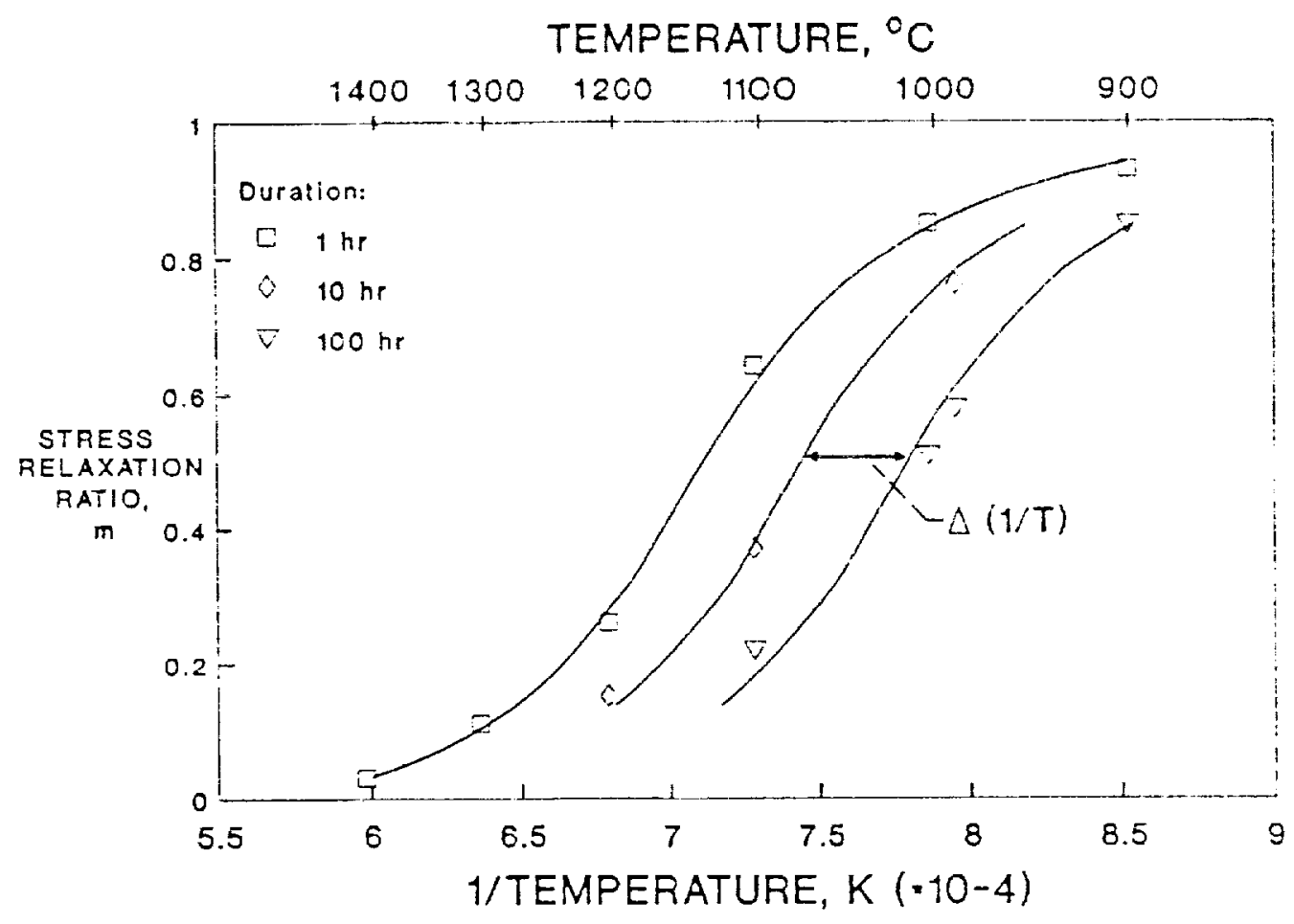

Figure 4.-Stress relaxation ratio versus reciprocal temperature for SCS 6 fibers in air for 1,10 , and 100 hour tests. ( $\epsilon_{0} \sim 0.3$ percent) 


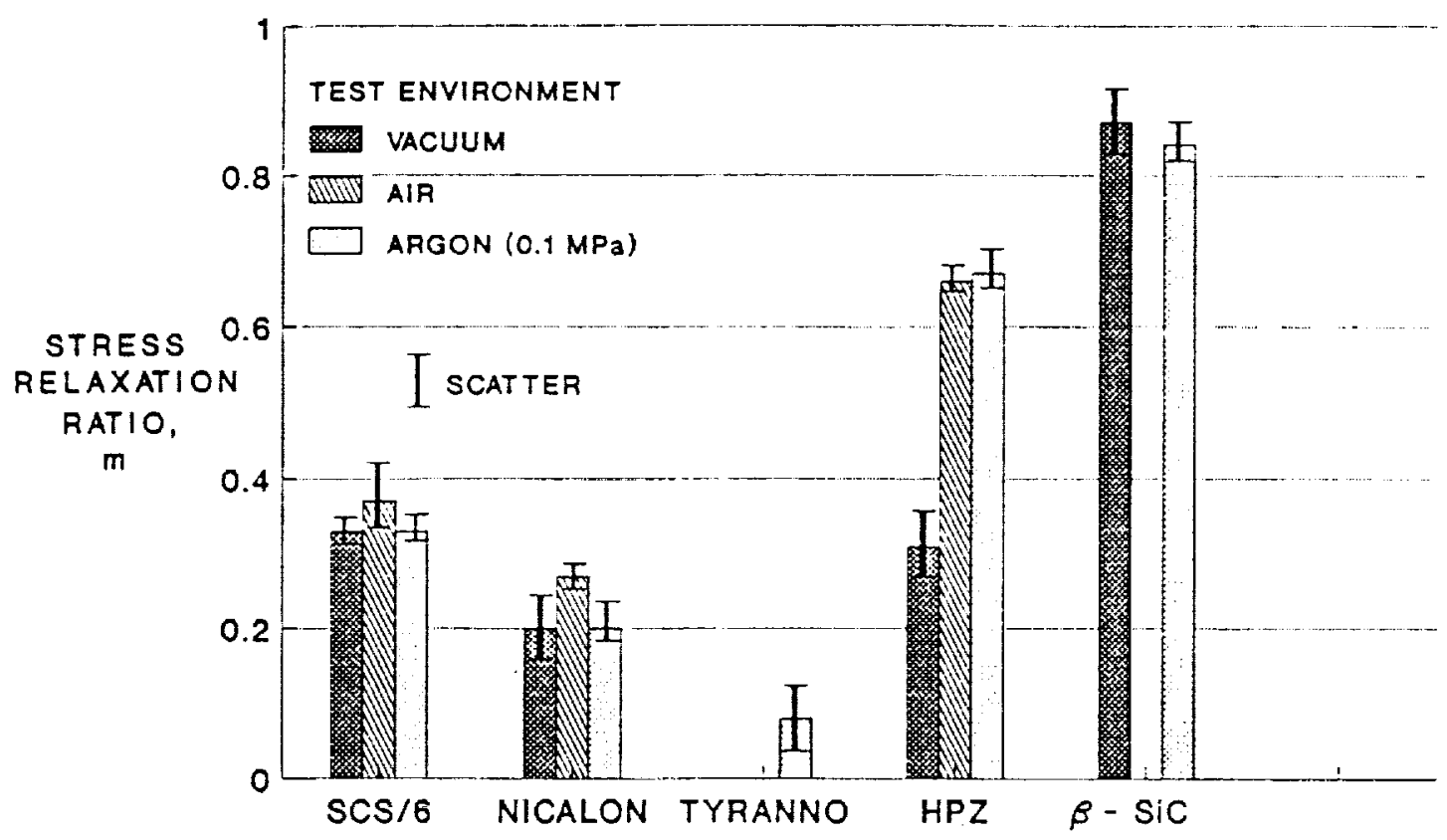

(a) $1200^{\circ} \mathrm{C}$

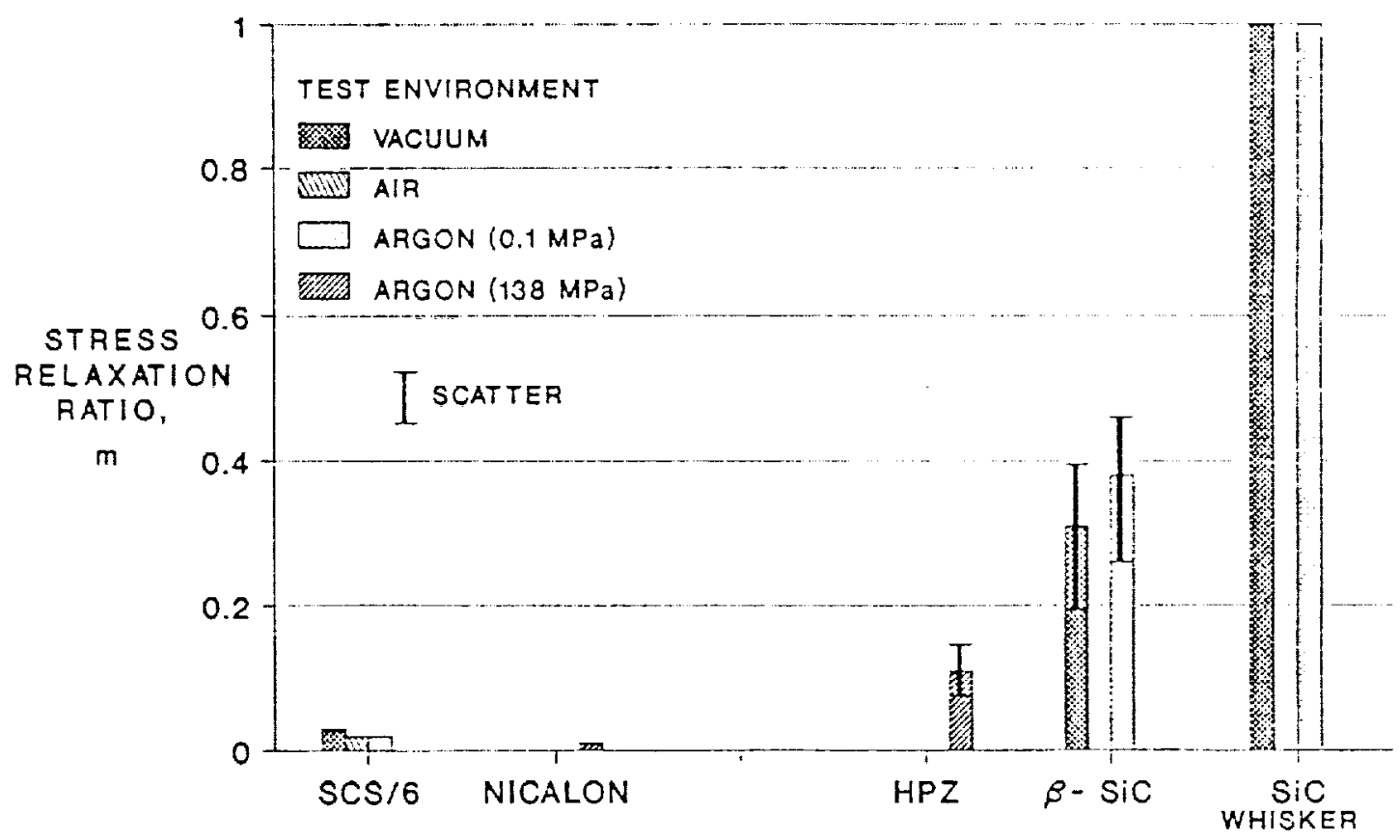

(b) $1400^{\circ} \mathrm{C}$

Figure 5.-One hour stress relaxation ratio comparison for various fibers and environments at $1200^{\circ} \mathrm{C}(\mathrm{a})$ and $1400^{\circ} \mathrm{C}(\mathrm{b})$. Between 4 and 8 fibers were treated for each bar. Surface strain was $\sim 0.3$ percent for all fibers except for the SiC whisker $(0.05$ to 0.15 percent) 


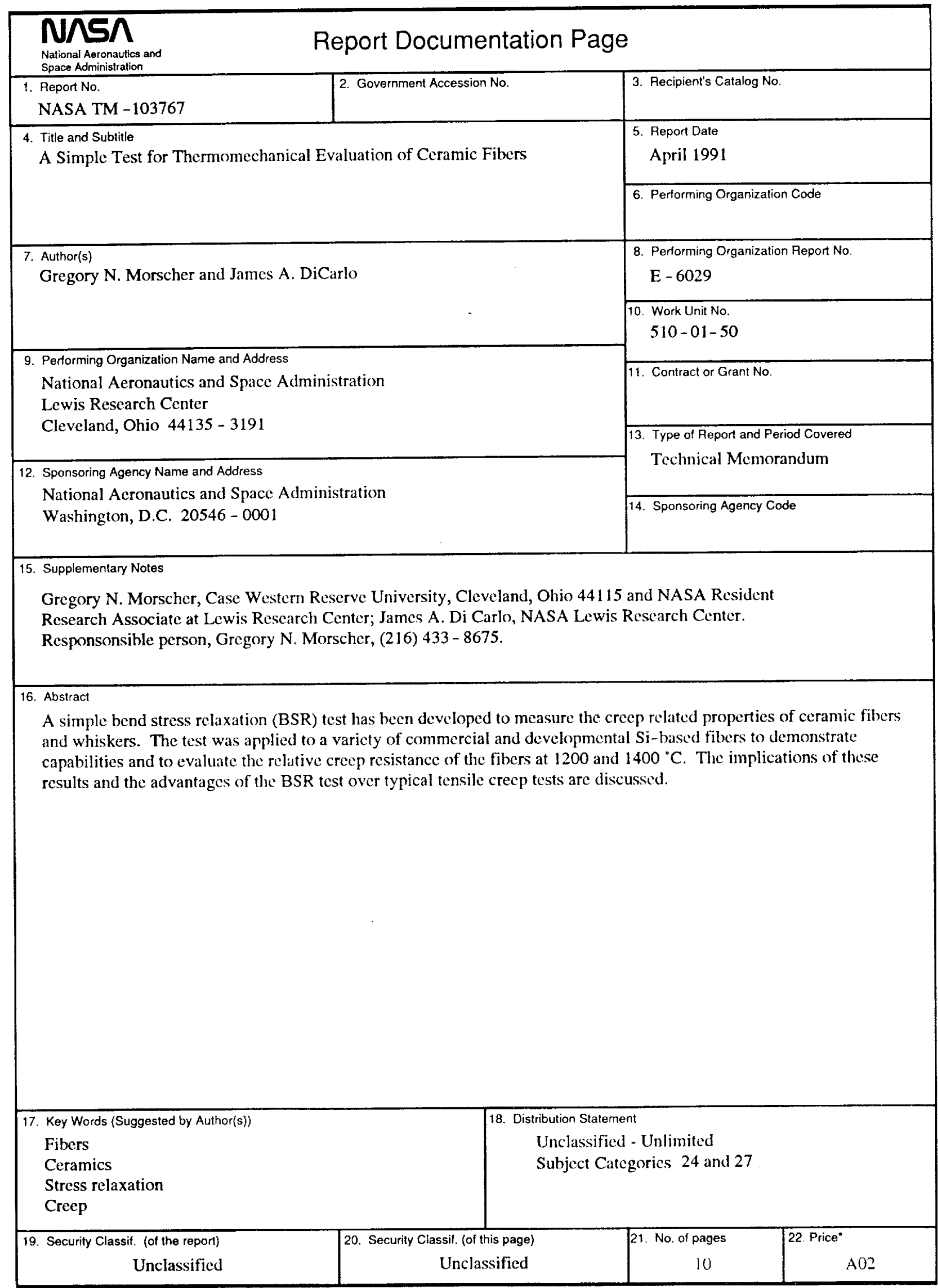


